University of Nebraska - Lincoln

DigitalCommons@University of Nebraska - Lincoln

USDA National Wildlife Research Center - Staff

Publications

U.S. Department of Agriculture: Animal and Plant Health Inspection Service

2019

Evaluation of two unmanned aircraft systems as tools for protecting crops from blackbird damage

Lucas J. Wandrie

North Dakota State University, lucas.wandrie@westwoodps.com

Page E. Klug

USDA APHIS Wildlife Services

Mark E. Clark

North Dakota State University

Follow this and additional works at: https://digitalcommons.unl.edu/icwdm_usdanwrc

Part of the Life Sciences Commons

Wandrie, Lucas J.; Klug, Page E.; and Clark, Mark E., "Evaluation of two unmanned aircraft systems as tools for protecting crops from blackbird damage" (2019). USDA National Wildlife Research Center - Staff Publications. 2208.

https://digitalcommons.unl.edu/icwdm_usdanwrc/2208

This Article is brought to you for free and open access by the U.S. Department of Agriculture: Animal and Plant Health Inspection Service at DigitalCommons@University of Nebraska - Lincoln. It has been accepted for inclusion in USDA National Wildlife Research Center - Staff Publications by an authorized administrator of DigitalCommons@University of Nebraska - Lincoln. 


\title{
Evaluation of two unmanned aircraft systems as tools for protecting crops from blackbird damage
}

\author{
Lucas J. Wandrie ${ }^{\mathrm{a}, *, 1}$, Page E. Klug ${ }^{\mathrm{b}}$, Mark E. Clark ${ }^{\mathrm{a}}$ \\ ${ }^{a}$ North Dakota State University, Department of Biological Sciences, 1340 Bolley Dr. Fargo, ND, USA \\ ${ }^{\mathrm{b}}$ United States Department of Agriculture, Animal and Plant Health Inspection Service, Wildlife Services, National Wildlife Research Center, North Dakota Field Station, \\ North Dakota State University, 1340 Bolley Dr. Fargo, ND, USA
}

\section{A R T I C L E I N F O}

\section{Keywords:}

Unmanned aerial vehicles

Frightening devices

Human-wildlife conflict

Wildlife damage

UAS

\begin{abstract}
A B S T R A C T
In response to a need for mitigating blackbird damage to crops, we evaluated the effectiveness of two unmanned aircraft systems (UAS or drones) to protect crops from blackbird damage. UAS are known to elicit behavioral and physiological responses in wildlife and have been proposed as a means to protect row crop agriculture from avian pest depredation. We evaluated the behavioral responses of captive and free-ranging red-winged blackbirds to a fixed-wing and a rotary-wing (multi-rotor, quadcopter) UAS by comparing preflight behaviors to behaviors during UAS approach. Due to the flight limitations of the respective UAS, the fixed-wing and rotarywing were evaluated at different altitudes. Behavioral responses of captive and free-ranging blackbirds to approaching UAS were categorized as no response, alertness, or attempted escape/flight. Neither captive nor freeranging flocks of red-winged blackbirds displayed behavioral responses to approaches by the fixed-wing UAS when flown at or above $52 \mathrm{~m}$ above ground level (AGL). However, both captive and free-ranging flocks exhibited behavioral responses to the rotary-wing UAS when flown within $30 \mathrm{~m}$ AGL. Behavioral responses of blackbirds to the rotary-wing UAS were more pronounced with lower altitude approaches. Our findings suggest that UAS have the potential to modify blackbird behavior in a way that may reduce sunflower crop depredation.
\end{abstract}

\section{Introduction}

Damage to food crops by migratory birds across North America results in significant costs to producers. These migratory bird communities capitalize on the seasonal production and concentration of high quality food sources. Blackbird (Icteridae) damage to agricultural crops is a significant problem for farmers across North America (Shwiff et al., 2017). During the non-breeding season blackbirds form large flocks that often forage in mature agricultural crops (Dolbeer et al., 1978). Annual damage estimates to sunflower crops were US $\$ 3.5$ million, for North Dakota alone during a 2009-2010 study (Klosterman et al., 2013). Thus, methods to manage blackbird damage to crops are needed, and public preference for non-lethal methods are preferred (Linz et al., 2011; McIvor and Conover, 1994).

Devices such as unmanned aircraft systems (UAS) have the potential to be used as a non-lethal control of blackbirds on agricultural crops (Klug, 2017). Recently, UAS have also been employed for low-altitude surveys of animal populations (Chabot and Bird, 2012; Sardá-Palomera et al., 2012; Watts et al., 2010) and have been proposed as a tool to scare pest bird species from airports, landfills, and agricultural fields. For example, autonomously controlled UAS equipped with scare tactic devices have been suggested as a method for controlling pest bird populations in vineyards (Grimm et al., 2012) and other specialty crops (Ampatzidis et al., 2015). Vehicles, such as UAS, elicit behavioral responses in birds (Bernhardt et al., 2010; Blackwell et al. 2009, 2012; DeVault et al., 2014; Pomeroy et al., 2015), and therefore, could be used as a management tool to deter birds from foraging in crops.

Although UAS have been proposed as a means to control bird pests in crops, as of yet there have not been any empirical studies that assess potential effectiveness. The results of previous UAS-wildlife interaction studies suggest that UAS flights are able to elicit antipredator behavioral responses in birds and other wildlife species and may be effective with blackbirds when used for hazing (e.g., Blackwell et al., 2012; Ditmer et al., 2015; Pomeroy et al., 2015; Rümmler et al., 2015; Vas et al., 2015). Additionally, our research using video simulations of UAS suggests that blackbirds would respond to approaches of real-life UAS (Wandrie et al., 2016).

To determine the applicability of using UAS as a means of hazing

\footnotetext{
${ }^{*}$ Corresponding author.

E-mail address: lucas.wandrie@westwoodps.com (L.J. Wandrie).

${ }^{1}$ Present address: Westwood Professional Services, Environmental Services, 12701 Whitewater Dr., Suite 300 Minnetonka, MN, USA.
} 
avian pests in crops, we selected representative models of typical UAS platforms (e.g., fixed-wing and rotary-wing) that are currently available to consumers. The objectives of this study were to 1 ) determine and compare the behavioral responses of red-winged blackbirds housed within semi-natural enclosures to different hazing approaches by fixedwing and rotary-wing UAS and 2) determine and compare the effectiveness of fixed-wing and rotary-wing UAS as scare devices for deterring free-ranging red-winged blackbirds from crops.

\section{Methods}

\subsection{UAS platforms}

The UAS platforms used in this study were the Fourthwing Vireo (fixed-wing) and the DJI Inspire (rotary-wing). The fixed-wing UAS software enables flight at or above $52 \mathrm{~m}$ above ground level (AGL) and attempts to maintain a constant speed of $53 \mathrm{~km} / \mathrm{h}$. In contrast, the rotary-wing UAS does not have a minimum altitude capability for flight and can achieve speeds of up to $79 \mathrm{~km} / \mathrm{h}$. Peak sound levels at $2 \mathrm{~m}$ AGL are $79.8 \mathrm{~dB}$ for the rotary-wing UAS and $66.6 \mathrm{~dB}$ for the fixed-wing UAS. The differences in the flight performance of the two UAS platforms allowed for the testing of different hazing approaches.

\subsection{Captive study}

We used wild-caught male red-winged blackbirds from a previous study for the captive trials. These birds were caught as hatch-year birds and housed in the North Dakota State University (NDSU) Conservation Research Center for a year prior to the UAS experimental trials. The Conservation Research Center is a roofed outdoor aviary located at the Red River Zoo in Fargo, ND. Birds were randomly assigned to five groups of three individuals and placed in an outdoor enclosure $(144.78 \times 165.1 \times 152.4 \mathrm{~cm})$ to simulate semi-natural conditions and allowed to acclimate for 30 -min prior to the experiment. Trials were conducted in a standing sunflower plot at the NDSU Agronomy Seed Farm in Casselton, ND.

Birds were exposed to the following four treatments: 1) fixed-wing UAS horizontal fly-over (52 m AGL); 2) rotary-wing UAS horizontal flyover (30 m AGL); 3) rotary-wing UAS horizontal fly-over (15 m AGL); and 4) rotary-wing vertical decent (30-5 m AGL; Fig. 1). Approach speeds of the fixed-wing and rotary-wing aircraft were 53.1 and $67.7-69.1 \mathrm{~km} / \mathrm{h}$, respectively, excluding the $30-5 \mathrm{~m}$ AGL descent of the rotary-wing UAS where descent speed was $14.4 \mathrm{~km} / \mathrm{h}$. Three groups were exposed to all UAS approach treatments, and two were exposed only to the rotary-wing treatments. Groups were exposed to treatments following the sequential order as stated above within a 30-min period. All approaches were made from the south (Fig. 1). We elected to use a non-random order to avoid a scenario where a low-altitude approach was the first treatment. A low-altitude approach was the most likely to elicit a response, thereby, negating subsequent treatments. After making a pass, UAS were directed away from the enclosure and changes in the altitude of the rotary-wing UAS were made $80 \mathrm{~m}$ from the enclosure near the pilot. Behavioral responses were recorded with video cameras (Drift Ghost - S HD, London, England) positioned to the south and east of the enclosure. Bird behaviors during a 1-min period prior to any UAS approaches were scored and used as a control comparison.

\subsection{Free-ranging study}

Field tests of free-ranging blackbird disturbance from UAS were performed between October and November 2016. We located 21 flocks of free-ranging blackbirds that were foraging or loafing in or around row crops, and with permission from landowners performed flights above 13 of those flocks to assess blackbird behavioral responses to UAS approaches. Numbers of birds within flocks ranged from several hundred to several thousand birds based on visual estimates.

The behaviors of the eight flocks that were not approached with UAS were scored and used as controls. The fixed-wing was flown horizontally at 67 or $52 \mathrm{~m}$ AGL and the rotary-wing was flown horizontally at 30 or $15 \mathrm{~m}$ AGL. We elected to use non-random order for the treatments because previous research on UAS-wildlife interactions suggested that low-altitude approaches were the most likely to induce a response from target animals (McEvoy et al., 2016; Pomeroy et al., 2015). Therefore, if the low-altitude treatment scared the flock away, no other treatments could be tested. We considered different altitudes during approach for each UAS to be a separate treatment. The UAS were launched at a distance deemed sufficient to not disturb flocks prior to strafing approaches $(\overline{\mathrm{x}} \pm \mathrm{SE}=342.31 \pm 67.18 \mathrm{~m})$. Each UAS
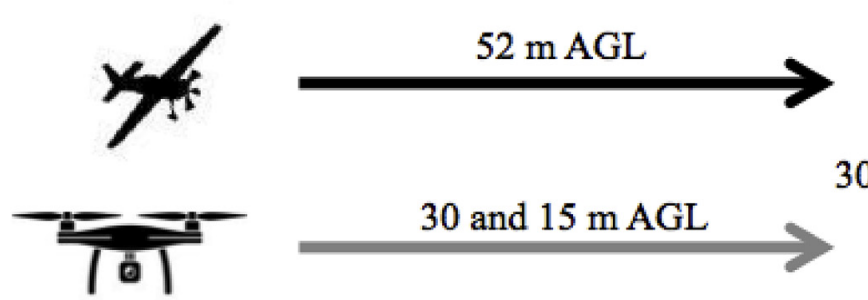

$30-5 \mathrm{~m}$ AGL descent
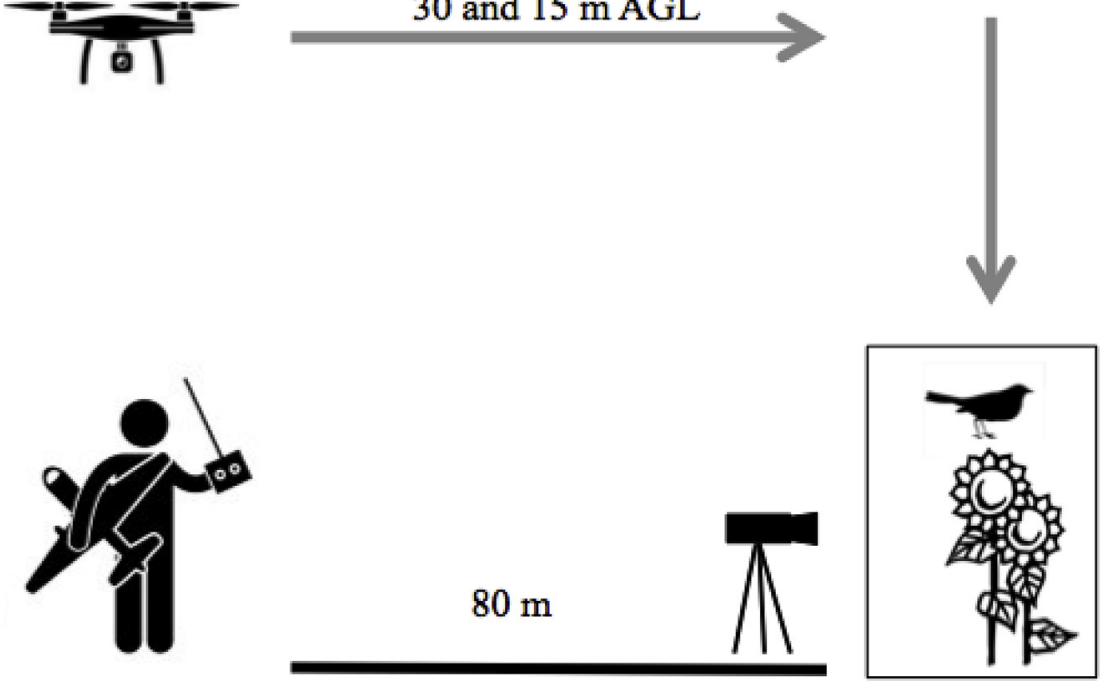

$80 \mathrm{~m}$

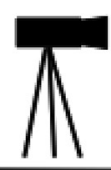

Fig. 1. Schematic representation of the experimental design for the captive study. There were five standing sunflower plants within the enclosure. The pilot was obstructed from view of the captive redwinged blackbirds by standing sunflower. All UAS approaches were from the south and cameras were stationed to the south and east of the enclosure. The fixed-wing UAS was flown first at $52 \mathrm{~m} \mathrm{AGL}$, followed by the rotary-wing UAS at 30 then $15 \mathrm{~m}$ AGL, and lastly the rotary-wing descent approach. All changes in altitude of the rotary-wing UAS aside from the descent were made beyond the view of the captive birds near the pilot. 
approach, or treatment, was completed at least three times (i.e., at a minimum of three flocks). Approach speeds of the fixed-wing and rotary-wing UAS were 53.1 and $67.7-69.1 \mathrm{~km} / \mathrm{h}$, respectively. We recorded and compared the behavioral responses of blackbirds to the different UAS platforms (e.g., no behavioral response or avoidance behavior).

\subsection{Behavioral classifications}

Behaviors were classified as 1) no response if there was no response to UAS, 2) alert if birds produced alarm calls or briefly lifted-off vertically before returning to forage, and 3) escape response if the birds took flight and flew away from the approaching UAS (McEvoy et al., 2016).

\subsection{Statistical analysis}

We compared the behavioral response scores of blackbirds in both the captive and free-ranging studies for each UAS approach treatment to that of controls using contingency analyses (i.e., Likelihood Ratio). We also compared the ability among UAS treatments (e.g., $15 \mathrm{~m}$ AGL to $30 \mathrm{~m}$ AGL) to elicit responses in blackbirds using contingency analyses. If the UAS treatment elicited a response in the captive study, we pooled alert and escape behavioral categories to determine the ability of the approach technique to elicit a change in behavior. If the UAS treatment elicited a response in the free-ranging study, we pooled alert and flight behavioral categories to determine the ability of the approach technique to elicit a change in behavior. We also evaluated how altitude affected the ability of each UAS to elicit the flight response in the free ranging study. Post-hoc pooling analyses were done, in part, to evaluate the robustness of any differences among treatment groups to the behavioral controls. Statistical analyses were performed in JMP statistical software (SAS Institute Inc., Cary, NC, USA).

\section{Results}

\subsection{Captive study}

We performed flights over five captive flocks with the rotary-wing UAS in sequential order of $30 \mathrm{~m}$ AGL, $15 \mathrm{~m} \mathrm{AGL}$, and 30 to $5 \mathrm{~m}$ AGL descending. Descent approaches were made toward the flock in the enclosure. Of those five flocks, three were also exposed to the fixedwing UAS at $52 \mathrm{~m}$ AGL before approaching with the rotary-wing UAS. During the sequence of flights, a response was never followed by no response nor was an escape response followed by a alert response. Fixed-wing approaches and controls elicited no response by captive birds (Table 1a). During rotary-wing approaches blackbird flocks showed varied responses based on treatment, the most pronounced responses were during the 30 to $5 \mathrm{~m}$ descent (Table $1 \mathrm{a}$ ). There were no differences in behavioral responses between control and the rotarywing approaches at $30 \mathrm{~m}$ AGL. Blackbirds were more responsive to rotary-wing approaches at $15 \mathrm{~m}$ AGL compared to controls $(60 \%$ response to rotary-wing treatment versus $0 \%$ response to control; $\chi_{(\mathrm{df}=1}^{2}$, $n=10)=5.487, P=0.0192)$ but were not more likely to display an escape response $(20 \%$ exhibiting escape response to rotary-wing treatment versus $0 \%$ escape response to control). Compared to control behaviors, blackbird groups were more responsive to the rotary-wing descent approach $(80 \%$ response to rotary-wing treatment versus $0 \%$ response to control; $\left.\chi_{(\mathrm{df}=1, n=10)}^{2}=8.456, P=0.0036\right)$ and were more likely to display an escape response ( $80 \%$ response to rotary-wing treatment versus $0 \%$ response to control; $\left.\chi_{(\mathrm{df}=1,}^{2} n=10\right)=8.456$, $P=0.0036$ ). There were no differences in behavioral responses to rotary-wing approaches at 30 and $15 \mathrm{~m}$ AGL. Rotary-wing altitude did not influence the likelihood of eliciting a behavioral response; however, rotary-wing descent approaches were more likely to elicit an escape response than rotary-wing approaches at $30 \mathrm{~m}$ AGL (80\% escape
Table 1

Behavioral response scores of captive (a) and free-ranging (b) red-winged blackbird flocks during control periods and UAS approaches at varying altitudes. Three flocks of captive red-winged blackbirds (a) received all four treatments and two flocks received only the rotary-wing treatments. Thirteen flocks of free-ranging blackbirds (b) were approached by UAS, one flock was exposed to the fixed-wing treatment solely, two flocks received all four treatments, eight flocks received both of the rotary-wing treatments, and two flocks only received the $30 \mathrm{~m}$ rotary-wing treatment. Controls groups (b) include the behaviors of eight flocks that were not exposed to UAS treatment. Values indicate the number of groups that responded according to the behavioral classifications. Values in parentheses indicate the percentage of flocks that exhibited a behavioral classification per treatment.

\begin{tabular}{llll}
\hline Treatment (AGL) & \multicolumn{2}{l}{ Behavioral response } & \\
\hline (a) & No response & Alert & Escape \\
\hline Control & $5(100)$ & $0(0)$ & $0(0)$ \\
Fixed-wing (52 m) & $3(100)$ & $0(0)$ & $0(0)$ \\
Rotary-wing (30 m) & $3(60)$ & $1(20)$ & $1(20)$ \\
Rotary-wing (15 m) & $2(40)$ & $2(40)$ & $1(20)$ \\
Rotary-wing descent & $1(20)$ & $0(0)$ & $4(80)$ \\
\hline (b) & No response & Alert & Flight \\
\hline Control & $8(100)$ & $0(0)$ & $0(0)$ \\
Fixed-wing (67 m) & $3(100)$ & $\begin{array}{l}0(0) \\
0(0)\end{array}$ & $0(0)$ \\
Fixed-wing (52 m) & $3(100)$ & $6(50)$ & $4(33)$ \\
Rotary-wing (30 m) & $2(17)$ & $1(10)$ & $8(80)$ \\
Rotary-wing (15 m) & $1(10)$ & & \\
\hline
\end{tabular}

response to descent treatment versus $20 \%$ response to $30 \mathrm{~m}$ treatment; $\left.\chi_{(\mathrm{df}=1, n=10)}^{2}=3.855, P=0.0496\right)$ or $15 \mathrm{~m}$ AGL ( $80 \%$ escape response to descent treatment versus $20 \%$ response to $15 \mathrm{~m}$ treatment; $\chi_{(\mathrm{df}=1}^{2}$, $n=10)=3.855, P=0.0496)$.

\subsection{Free-ranging study}

We performed a total of six flights over three free-ranging flocks with the fixed-wing UAS, three at $67 \mathrm{~m}$ AGL and three at $52 \mathrm{~m}$ AGL. With the rotary-wing we flew 12 flights and 10 flights over free-ranging flocks at 30 and $15 \mathrm{~m}$ AGL, respectively. One flock was exposed to the fixed-wing treatment solely, two flocks received all four treatments, eight flocks received both of the rotary-wing treatments, and two flocks received only the $30 \mathrm{~m}$ rotary-wing treatment. During the sequence of flights a response was never followed by no response nor was an escape response followed by an alert response. Thus, flight order did not influence responses. All behavioral responses for the eight control periods (i.e., flocks not subjected to UAS approaches) and the fixed-wing approaches at both altitudes were scored as no response (Table $1 \mathrm{~b}$ ). Flocks approached by the rotary-wing at $30 \mathrm{~m}$ AGL $(\mathrm{n}=12)$ were more responsive compared to controls ( $83 \%$ response to rotary-wing treatment versus $0 \%$ response to control; $\chi_{(\mathrm{df}=1, n=20)}^{2}=16.912, P<0.0001$ ) and were more likely to exhibit an escape response (33\% response to rotary-wing treatment versus $0 \%$ response to control; $\chi_{(\mathrm{df}=1}^{2}$, $n=20)=4.740, P=0.0295$ ). Flocks approached by the rotary-wing at 15 m AGL $(n=10)$ were more responsive than controls ( $90 \%$ response to rotary-wing treatment versus $0 \%$ response to control; $\chi_{(\mathrm{df}=1}^{2}$, $n=18)=18.452, P<0.0001)$ and were more likely to exhibit an escape response $(80 \%$ response to rotary-wing treatment versus $0 \%$ response to control; $\left.\chi_{\text {Likelihood ratio }(\mathrm{df}=1, n=18)}^{2}=14.723, P<0.001\right)$. When approached by the rotary-wing UAS at $15 \mathrm{~m}$ AGL flocks were more likely to escape than when approached at $30 \mathrm{~m}$ AGL $(80 \%$ response to $30 \mathrm{~m}$ treatment versus $33 \%$ response to $15 \mathrm{~m}$ treatment; $\chi \stackrel{2}{(\mathrm{df}=1 \text {, }}$ $n=22)=5.032, P=0.025$; Fig. 2). 


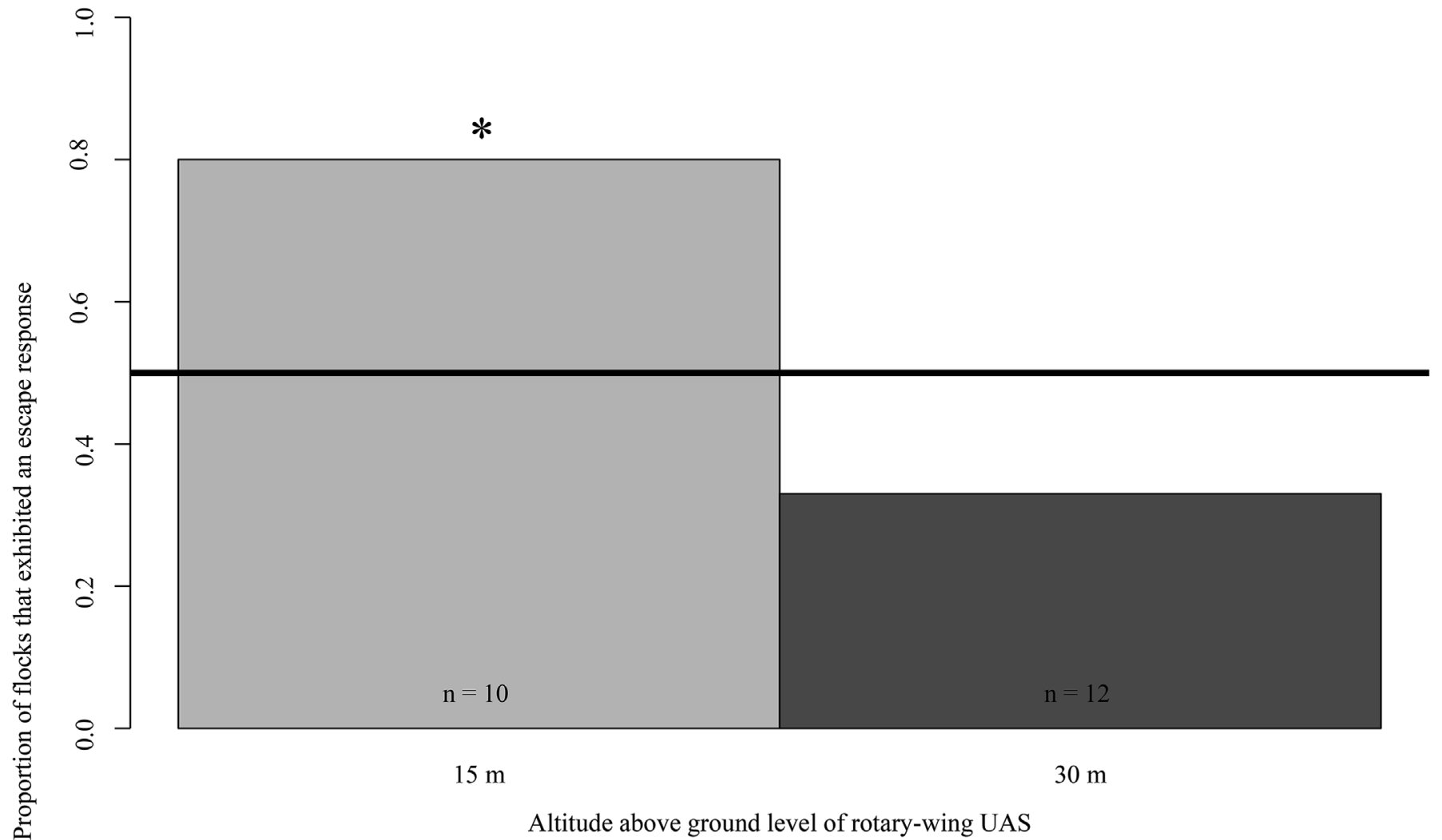

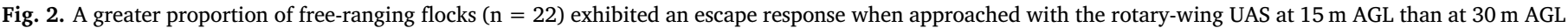
$(\chi \underset{(\mathrm{df}=1, \mathrm{n}=22)}{2}=5.032, P=0.025)$. Escape was considered a more pronounced response than alertness. The asterisk indicates significance level below 0.05 .

\section{Discussion}

Most studies involving UAS-wildlife interactions have focused on determining how to minimize disturbance to wildlife (Drever et al., 2015; McEvoy et al., 2016; Vas et al., 2015). We found that in some cases blackbird flocks will respond to UAS approaches with avoidance behavior. Our results also suggest that it is possible to deploy UAS over flocks of non-breeding blackbirds without inducing behavioral responses, if desired for population monitoring purposes. Therefore, our results have implications for pest management and conservation practices.

The results from our study approaching captive blackbirds with a rotary-wing UAS were similar to those found by Vas et al. (2015) using mallards (Anas platyrhynchos), flamingos (Phoenicopterus roseus), and common greenshanks (Tringa nebularia). Vas et al. (2015) found that a rotary-wing UAS with a vertical approach elicited more pronounced responses than did other approach techniques. However, it should be noted that Vas et al. (2015) compared different angular approaches (i.e., 20, 30, 60 and $90^{\circ}$ ) and we used horizontal and vertical approaches. During our study, captive blackbirds only responded to horizontal rotary-wing approaches at $30 \mathrm{~m}$ AGL with alert or escape behaviors in $40 \%$ of trials (two of five groups), which was not different than $0 \%$ of control trials (zero of five groups). Blackbirds responded to horizontal rotary-wing approaches at $15 \mathrm{~m}$ AGL in $60 \%$ of trials (three of five groups) and to vertical approaches with the rotary-wing in $80 \%$ of trials (four of five groups [all escape]). We agree with Vas et al. (2015) that the vertical approach may be more disturbing because it may be associated with a predator attack. Other possibilities are that the birds found the noise level of the rotating propellers disturbing at that proximity or were disturbed by the rotor wash.

Behavioral responses of free-ranging blackbird flocks to UAS approaches were similar to those found by Rümmler et al. (2015) in wild colonies of Adélie penguins (Pygoscelis adelie). Adélie penguins were more responsive to UAS approaches at lower altitudes (Rümmler et al., 2015). Interestingly, in our study, free-ranging flocks of blackbirds were more responsive to UAS approaches than were the captive flocks. We believe that this may indicate some level of habituation to vehicle disturbance from the captive flocks that were housed at an outdoor aviary at a public zoo, a loss of responsiveness to potentially threatening stimuli due to long-term captivity, or an awareness of the restrictive nature of an enclosure. Other studies suggest that behavioral responses of captive individuals to potentially threatening stimuli are reduced when compared to wild counterparts (Blanchard et al. 1986, 1998). Therefore, caution should be used when extrapolating behavioral responses of captive animals to those of free-ranging populations. It is unknown if free-ranging flocks of blackbirds will habituate to UAS hazing techniques, but results from Rümmler et al. (2015) suggest that habituation, at least in the short-term (i.e., repeated flyovers over the same group of birds on the same day), may not happen.

Neither captive nor free-ranging blackbirds showed behavioral responses to the fixed-wing UAS. The UAS flight capabilities, specifically the inability to program flights less than $52 \mathrm{~m}$ AGL for the fixed-winged UAS may limit the usefulness of this platform for hazing purposes. It is possible that at altitudes of $52 \mathrm{~m}$ and greater, UAS were too distant to be considered a threat by the birds. The fixed-wing UAS used in this study was $13.2 \mathrm{~dB}$ quieter than the rotary-wing at $2 \mathrm{~m}$ AGL. As such, the birds may have been exhibiting behavioral responses to the noise disturbance produced by the rotary-wing UAS, as noise level appears to influence behavioral responses to UAS (Mulero-Pázmány et al., 2017). In a review of UAS-wildlife interactions, Mulero-Pázmány et al. (2017) suggest that louder UAS (e.g., fuel-powered) are more likely to induce behavioral responses than quieter UAS (e.g., electric-powered). Both of the UAS used in our study were electric-powered but the rotary-wing UAS was noticeably louder than the fixed-wing UAS.

It is possible that a fixed-wing platform capable of maintaining lowaltitude flights comparable to the rotary-wing used in this study would 
elicit similar behavioral responses in blackbirds. During a test of UAS disturbance in waterfowl, McEvoy et al. (2016) found that of the five aircraft tested (three fixed-wing and two rotary-wing), the fixed-wing that superficially resembled the wing-shape of a local avian predator elicited the most pronounced avoidance responses. Interestingly, the other two fixed-wing UAS used in McEvoy et al. (2016) did not elicit a response in waterfowl when flown $\geq 70 \mathrm{~m}$ and only elicited an alert response when flown at the minimal flight altitude of $60 \mathrm{~m}$. They suggested that the lack of response to the other two fixed-wing UAS was due to similar shape and size to that of local swan species, but may just be an artifact of flight altitude.

For UAS to be effective in protecting crops from blackbird depredation modifications to the physical UAS or methodology may be required. Our data suggest that approaching flocks at lower altitudes elicits behavioral responses. Potential modifications to UAS include the addition of an audio system (e.g., to produce distress or alarm calls or firearm discharge sounds [Berge et al., 2007; Delwiche et al., 2007]), lasers (Werner and Clark, 2006) or lights (Blackwell and Bernhardt, 2004; Blackwell et al. 2009, 2012), or shapes mimicking an aerial predator (Blackwell et al., 2012). Additionally, a fully automated system, similar to that proposed by Grimm et al. (2012) or Ampatzidis et al. (2015) may be a more effective methodology, in that, it could potentially reduce labor and be programmed in ways to reduce the chance of blackbirds habituating to the UAS. Though such an automated system would need to be capable of directly approaching flocks, as indirect (e.g., lawn-mower) flight patterns are not effective for eliciting behavioral responses (Mulero-Pázmány et al., 2017). However, before such a system could be employed in the field, UAS will need to be engineered to meet the needs of producers, given current off-theshelf UAS do not have the on-board image processing ability to identify blackbird flocks. There may be difficulties with securing a company willing to develop a UAS specifically for the purpose of protecting crops from blackbird damage due to the small audience, as such, other options including alternate sizes and colors of UAS may be more tangible. Other logistical issues may need to be addressed due to environmental conditions during crop maturation (e.g., wind and temperature) and the need to minimize hazards to other low-flying aircraft (e.g., aircraft used for crop-dusting). Over the course of our field trials, it was not uncommon for ambient temperatures to be near or below $7^{\circ} \mathrm{C}$ and the battery packs of both UAS required an external heat source to reach operating temperature. Our results indicate that blackbirds will respond to approaches by rotary-wing UAS and those responses are more pronounced when the UAS approaches at lower altitudes. It should be noted, however, that our results are restricted to the specific UAS models used, and should not be generalized to a specific platform types because other studies have found that behavioral responses of animals to approaching UAS can vary based on the specific platform and are likely species and context specific (McEvoy et al., 2016; Pomeroy et al., 2015).

\section{Acknowledgements}

The U.S. Department of Agriculture, Animal and Plant Health Inspection Service, Wildlife Services, National Wildlife Research Center (7438-0020-CA; QA\#2348), the National Sunflower Association (16P02), the State Board of Agricultural Research (16-P02), and North Dakota State University supported this project. Reference to trade names does not imply endorsement of commercial products or exclusion of similar products by the United States government. Research was approved by the North Dakota State University Institutional Animal Care and Use Committee (IACUC \#A14068) and conducted under permits from the U.S. Fish and Wildlife Scientific Collecting Permit (\#MB39327B-0), the North Dakota Game and Fish Department (\#GNF03799268). North Dakota State University Research and Creative Activity approved all UAS flight plans. We would like to thank landowners and the North Dakota State University Agronomy Seed
Farm for their cooperation and allowing us to fly over their land. We also thank our undergraduate employees for their assistance. Drs. Wendy Reed, Gary Clambey and three anonymous reviewers provided helpful comments for revising an earlier version of this manuscript.

\section{References}

Ampatzidis, Y., Ward, J., Samara, O., 2015. Autonomous system for pest bird control in specialty crops using unmanned aerial vehicles. 2015. Am. Soc. Agric. Biol. Eng., $1521817481-6$.

Berge, A., Delwiche, M., Gorenzel, W.P., Salmon, T., 2007. Bird control in vineyards using alarm and distress calls. AJEV (Am. J. Enol. Vitic.) 58, 135-143.

Bernhardt, G.E., Blackwell, B.F., DeVault, T.L., Kutschbach-Brohl, L., 2010. Fatal injuries to birds from collisions with aircraft reveal anti-predator behaviours. Ibis 152, 830-834.

Blackwell, B.F., DeVault, T.L., Seamans, T.W., Lima, S.L., Baumhardt, P., FernándezJuricic, E., 2012. Exploiting avian vision with aircraft lighting to reduce bird strikes. J. Appl. Ecol. 49, 758-766.

Blackwell, B.F., Fernández-Juricic, E., Seamans, T.W., Dolan, T., 2009. Avian visual system configuration and behavioral response to object approach. Anim. Behav. 77, $673-684$.

Blackwell, B.F., Bernhardt, G.E., 2004. Efficacy of aircraft landing light in stimulating avoidance behavior in birds. J. Wildl. Manag. 68, 725-732.

Blanchard, R.J., Flannelly, K.J., Blanchard, D.C., 1986. Defensive behaviors of laboratory and wild Rattus norvegicus. J. Comp. Psychol. 100, 101-107.

Blanchard, R.J., Hebert, M.A., Ferrari, P.F., Palanza, P., Figueira, R., Blanchard, D.C., Parmigiani, S., 1998. Defensive behaviors in wild and laboratory (Swiss) mice: the mouse defense test battery. Physiol. Behav. 65, 201-209.

Chabot, D., Bird, D.M., 2012. Evaluation of an off-the-shelf unmanned aircraft system for surveying flocks of geese. Waterbirds 35, 170-174.

Delwiche, M.J., Houk, A., Gorenzel, W.P., Salmon, T.P., 2007. Control of crows in almonds by broadcast distress calls. Trans. ASABE (Am. Soc. Agric. Biol. Eng.) 50, 675-682.

DeVault, T.L., Blackwell, B.F., Seamans, T.W., Lima, S.L., Fernández-Juricic, E., 2014. Effects of vehicle speed on flight initiation by Turkey vultures: implications for birdvehicle collisions. PloS One 9, e87944.

Ditmer, M.A., Vincent, J.B., Werden, L.K., Tanner, J.C., Laske, T.G., Iaizzo, P.A., Garshelis, D.L., Fieberg, J.R., 2015. Bears show a physiological but limited behavioral response to unmanned aerial vehicles. Curr. Biol. 25, 2278-2283.

Dolbeer, R.A., Woronecki, P.P., Stickley Jr., A.R., White, S.B., 1978. Agricultural impact of a winter population of blackbirds and starlings. Wilson Bull. 90, 31-44.

Drever, M.C., Chabot, D., O'Hara, P.D., Thomas, J.D., Breault, A., Millikin, R.L., 2015. Evaluation of an unmanned rotorcraft to monitor wintering waterbirds and coastal habitats in British Columbia. Canada. J. Unmanned Veh. Syst. 3, 259-267.

Grimm, B.A., Lahneman, B.A., Cathcart, P.B., Elgin, R.C., Meshnik, G.L., Parmigiani, J.P., 2012. Autonomous unmanned aerial vehicle system for controlling pest bird population in vineyards. In: Proceedings of the ASME 2012 International Mechanical Engineering Congress and Exposition, pp. 499-505.

Klosterman, M.E., Linz, G.M., Slowik, A.A., Homan, H.J., 2013. Comparisons between blackbird damage to corn and sunflower in North Dakota. Crop Protect. 53, 1-5.

Klug, P.E., 2017. The future of blackbird management research. In: Linz, G.M., Avery, M.L., Dolbeer, R.A. (Eds.), Ecology and Management of Blackbirds (Icteridae) in North America. CRC Press/Taylor \& Francis, Boca Raton, Florida, USA, pp. 217-234.

Linz, G.M., Homan, H.J., Werner, S.J., Hagy, H.M., Bleier, W.J., 2011. Assessment of birdmanagement strategies to protect sunflowers. Bioscience 61, 960-970.

McEvoy, J.F., Hall, G.P., McDonald, P.G., 2016. Evaluation of unmanned aerial vehicle shape, flight path and camera type for waterfowl surveys: disturbance effects and species recognition. PeerJ. https://doi.org/10.7717/peerj.1831. e1831.

McIvor, D.E., Conover, M.R., 1994. Perceptions of farmers and non-farmers toward management of problem wildlife. Wildl. Soc. Bull. 22, 212-219.

Mulero-Pázmány, M., Jenni-Elermann, S., Strebel, N., Sattler, T., Negro, J.J., Tablado, Z 2017. Unmanned aircraft systems as a new source of disturbance for wildlife: a systematic review. PloS One 12 (6), e0178448.

Pomeroy, P., O'Connor, L., Davies, P., 2015. Assessing use of and reaction to unmanned aerial systems in gray and harbor seals during breeding and molt in the UK. J. Unmanned Veh. Syst. 3, 102-113.

Rümmler, M.-C., Mustafa, O., Maercker, J., Peter, H.-U., Esefeld, J., 2015. Measuring the influence of unmanned aerial vehicles on Adélie penguins. Polar Biol. https://doi. org $/ 10.1007 / \mathrm{s} 00300-015-1838-1$.

Sardá-Palomera, F., Bota, G., Viñolo, C., Pallarés, O., Sazatornil, V., Brotons, L., Gomáriz, S., Sardá, F., 2012. Fine-scale bird monitoring from light unmanned aircraft systems. Ibis $154,177-183$.

Shwiff, S.A., Ernest, K.L., Degroot, S.L., Anderson, A.M., 2017. The economic impact of blackbird damage to crops. In: Linz, G.M., Avery, M.L., Dolbeer, R.A. (Eds.), Ecology and Management of Blackbirds (Icteridae) in North America. CRC Press/Taylor \& Francis, Boca Raton, Florida, USA, pp. 207-216.

Vas, E., Lescroël, A., Duriez, O., Boguszewski, G., Grémillet, D., 2015. Approaching birds with drones: first experiments and ethical guidelines. Biol. Lett. 11, 20140754.

Wandrie, L.J., Reed, W., Clark, M., Karels, K., Klug, P., Linz, G., 2016. Behavioral responses of red-winged blackbirds to simulated predators: evidence of potential habituation to video stimuli. In: Timm, R.M., Baldwin, R.A. (Eds.), Proceedings of the 27th Vertebrate Pest Conference. University of California at Davis, Newport Beach, CA, pp. 253-257.

Watts, A.C., Perry, J.H., Smith, S.E., Burgess, M.A., Wilkinson, B.E., Szantoi, Z., Ifju, P.G., HF, Percival, H.F., 2010. Small unmanned aircraft systems for low-altitude aerial surveys. J. Wildl. Manag. 74, 1614-1619.

Werner, S.J., Clark, L., 2006. Effectiveness of a motion-activated laser hazing system for repelling captive Canada geese. Wildl. Soc. Bull. 34, 2-7. 